\title{
Cancer cells arise from bacteria
}

\author{
Qing-lin Dong ${ }^{*}$ (I) and Xiang-ying Xing
}

\begin{abstract}
Background: The origin of cancer cells is the most fundamental yet unresolved problem in cancer research. Cancer cells are thought to be transformed from the normal cells. However, recent studies reveal that the primary cancer cells (PCCs) for cancer initiation and secondary cancer cells (SCCS) for cancer progression are formed in but not transformed from the senescent normal and cancer cells, respectively. Nevertheless, the cellular mechanism of PCCs/SCCs formation is unclear. Here, based on the evidences (1) the nascent PCCs/SCCs are small and organelle-less resembling bacteria; (2) our finding that the cyanobacterium TDX16 acquires its algal host DNA and turns into a new alga TDX16DE by de novo organelle biogenesis, and (3) PCCs/SCCs formations share striking similarities with TDX16 development and transition, we propose the bacterial origin of cancer cells (BOCC).

Presentation of the hypothesis: The intracellular bacteria take up the DNAs of the senescent/necrotic normal cells/ PCCs and then develop into PCCs/SCCs by hybridizing the acquired DNAs with their own ones and expressing the hybrid genomes.

Testing the hypothesis: BOCC can be confirmed by testing BOCC-based predictions, such as normal cells with no intracellular bacteria can not "transform" into cancer cells in any conditions.

Implications of the hypothesis: According to BOCC theory: (1) cancer cells are new single-celled eukaryotes, which is why the hallmarks of cancer are mostly the characteristics of protists; (2) genetic changes and instabilities are not the causes, but the consequences of cancer cell formation; and (3) the common role of carcinogens, infectious agents and relating factors is inducing or related to cellular senescence rather than mutations. Therefore, BOCC theory provides new rationale and direction for cancer research, prevention and therapy.
\end{abstract}

Keywords: Bacteria, Cancer cells, Origin, Cellular senescence, DNA acquisition, Hybridization, Organelle biogenesis

\section{Background}

It is believed that cancer cells (PCCs) are altered normal cells formed by cell transformation. Based on this belief, extensive studies have been conducted, while the pathogenetic mechanism of cancer is, still, unclear [1]. Hence, this fundamental belief may be questionable. In the following sections, we (1) analyze the cellular processes of cancer cell formation described in the previous researches, (2) compare the similarities between cancer cell formation and cyanobacterium TDX16's development and transition [2, 3], and (3) propose BOCC hypothesis.

*Correspondence: qldong@hebut.edu.cn

Department of Bioengineering, Hebei University of Technology, Tianjin 300130, China

\section{Cancer cells are "senescence-escaping cells" with unknown origin}

Cancer cell formation is a complex event that can hardly be made clear in vivo. Since the landmark experiments showing that the normal cells in cultures gradually transformed into cancer cells $[4,5]$, in vitro cell transformation become the model experiment method to mimic in vivo cancer cell formation. The following studies manifested that in vitro cell transformation can occur spontaneously [6-9] or in the presence of physical stimuli [10], chemical carcinogens $[11,12]$ and viruses [13-17] in a similar pattern: the normal cells either completely failed to grow or divided for limited number of generations owing to the finite proliferative lifespan [18] and then became senescent and entered "crisis" [19], consequently most of the cells died, while only rare cells occasionally "escaped" cellular senescence or crisis and survived as the cancer cells, 
with altered morphology, ultrastructure, chromosomes $[6,20-22]$ and growth behavior properties [23, 24].

Nonetheless, the origin and developmental process of cancer cells are unknown, because cell transformations took a long period of time and the obtained cell cultures were composed of a mixture of small undifferentiated cells, polyploidy (hyperchromatic) giant cells (PGCs), flat multinucleated giant cells and sloughing, differentiating cells $[7,14,15,25-27]$, which made it difficult to track the trajectory of cancer cell development. In this case, cancer cells were postulated to be transformed from the normal cells, usually called "transformed cells".

\section{PCCs/SCCs were formed in but not transformed from the senescent normal cells/PCCs}

Recent studies revealed that the senescing normal cells turned into mitotically incapacitated PGCs, in which small nascent PCCs were being formed, and when PGCs burst, a large number of small PCCs were released [2834]. Hence, PCCs are formed in but not transformed from the senescent normal cells. Similarly, new small nascent SCCs were formed in the senescent polyploid giant cancer cells (PGCCs) [32, 35-46]. These results demonstrated that PCCs and SCCs formations share a common cellular mechanism.

Nevertheless, the cellular mechanism of how the small active PCCs/SCCs were formed in the senescent unviable PGCs/PGCCs is unclear, and remains a paradox. The common explanation is that small nuclei budded from the large PGCs/PGCCs nuclei, and then became small PCCs/SCCs by re-budding off from PGCs/PGCCs, or via asymmetric cytokinesis of PGCs/PGCCs. However, indeed, nuclear budding and cytokinesis were unachievable in the senescent PGCs/PGCCs, because no energy and membrane sources were available for sustaining such active actions.

Different from the common explanation, one study showed that small SCCs were formed in the nuclei of PGCCs [35]. Similar results were frequently reported in early researches: (1) SCCs-like nuclear inclusions were developed within PGCCs nuclei [47]; and (2) PCCs-like pycnotic cells and nuclear inclusions [48], intranuclear inclusion bodies [27, 49], intranuclear membrane-bound inclusions [23] and "micronuclei" [50] were formed in PGCs nuclei, which increased in number and distributed throughout PGCs after the large nuclei disappeared. As to how the intranuclear PCCs/SCCs were formed, it was speculated that SCCs were probably derived from the 'coiled bodies' [35], which were, however, delimited by membranes and thus also SCCs but not the membraneless coiled bodies [51]. Thus, there must be other precursors from which PCCs/SCCs were formed.
Since the small nascent PCCs/SCCs lack organelles and bear resemblances to the intracellular bacteria [52-61], it is likely that the small PCCs/SCCs were developed from the bacteria within PGCs/PGCCs. This notion may be intuitively unacceptable, but actually is possible in theory that eukaryotes originate from prokaryotes and supported by our finding that the cyanobacterium TDX16 (prokaryote) turned into a new alga TDX16-DE (eukaryote) $[2,3]$.

\section{PCCs/SCCs formation are similar to TDX16 development and transition}

Haematococcus pluvialis is a unicellular green alga, which grows well and synthesizes astaxanthin in the conditions of high irradiance and low temperature [62, 63]. Conversely, when cultivated under the adverse conditions of low irradiance and high temperature, the growth of $H$. pluvialis was inhibited [64]. Light microscopic observation showed that the enlarged $H$. pluvialis cells were undergoing senescence with no astaxanthin accumulation but chlorophyll reduction (Fig. 1A) and ultimately necrosis: the bloated senescent cell ruptured and liberated a massive blue spheroid consisting of countless small cyanobacterial cells (TDX16) (Fig. 1B). Transmission electron microscope observation revealed that very small premature TDX16 cells with electron dense dot-like heterogenous globular body (HGB) [3] multiplied by asymmetric division within the senescent/ necrotic $H$. pluvialis cell at the expense of the dissolved organelles and cytoplasm (Fig. 2A), and subsequently enlarged into small thylakoid-less TDX16 filling up the cellular space (Fig. 2B) [64]. The liberated TDX16 was light-sensitive and unstable, which changed slowly, maintained prokaryotic state, and displayed different statuses even in the same sporangium in the dim light (Fig. 2C), but turned readily and quickly into a small green alga (TDX16-DE) by de novo organelle biogenesis as light intensity elevated (Fig. 2D) [2,3]. TDX16-DE is a new species of green alga, containing only a double-envelopebounded nucleus, a chloroplast, one or more mitochondria and double-membrane-bounded vacuoles, but no other organelles (Fig. 2D) [3]. Sequencing results of $16 \mathrm{~S}$ rRNA (GenBank KJ599678.2) and Genome (GenBank NDGV00000000) indicate that TDX16 is a cyanobacterium resembling Chroococcidiopsis thermalis, which had acquired 9,017,401 bp DNAs with 10,301 genes from its host H. pluvialis. Thus, the reason for TDX16-to-TDX16DE transition is the hybridization of the obtained eukaryotic DNA and TDX16's prokaryotic ones, and expression of the hybrid genome [3].

TDX16's transition demonstrates that a prokaryotic cyanobacterium can obtain its senescent algal host's DNA and develop into a new eukaryotic alga. Since 

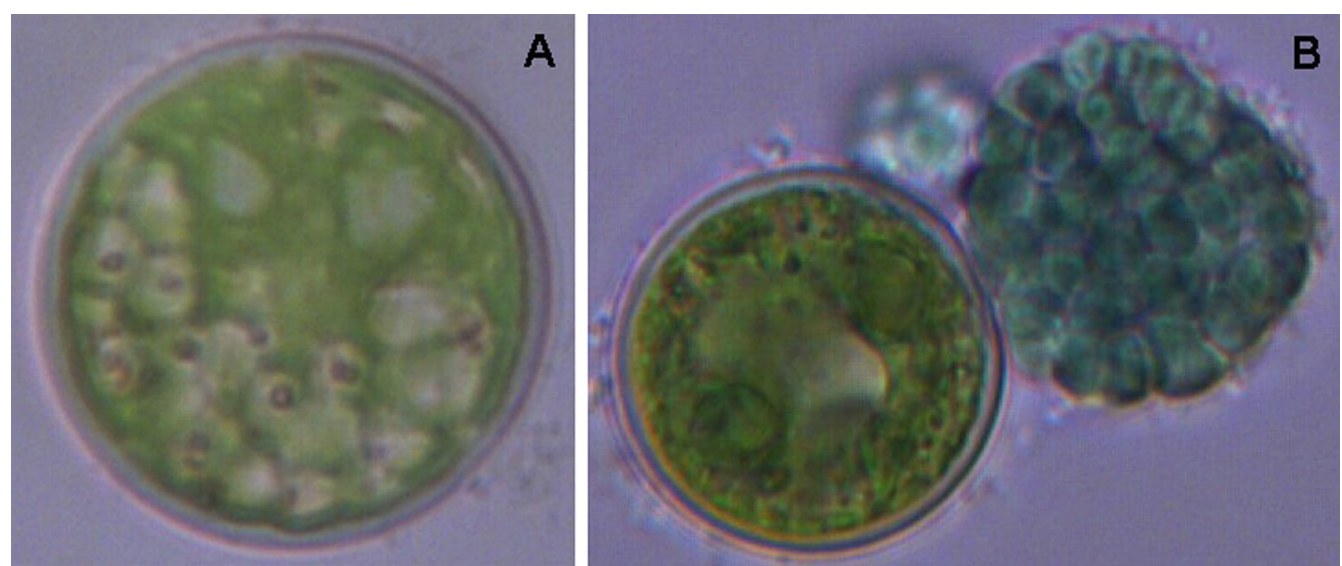

Fig. 1 Release of TDX16 from the senescent H. pluvialis cell. A An enlarged senescent H. pluvialis cell. B A massive blue spheroid (top right) with compacted TDX16 cells was released from the ruptured senescent $H$. pluvialis cell

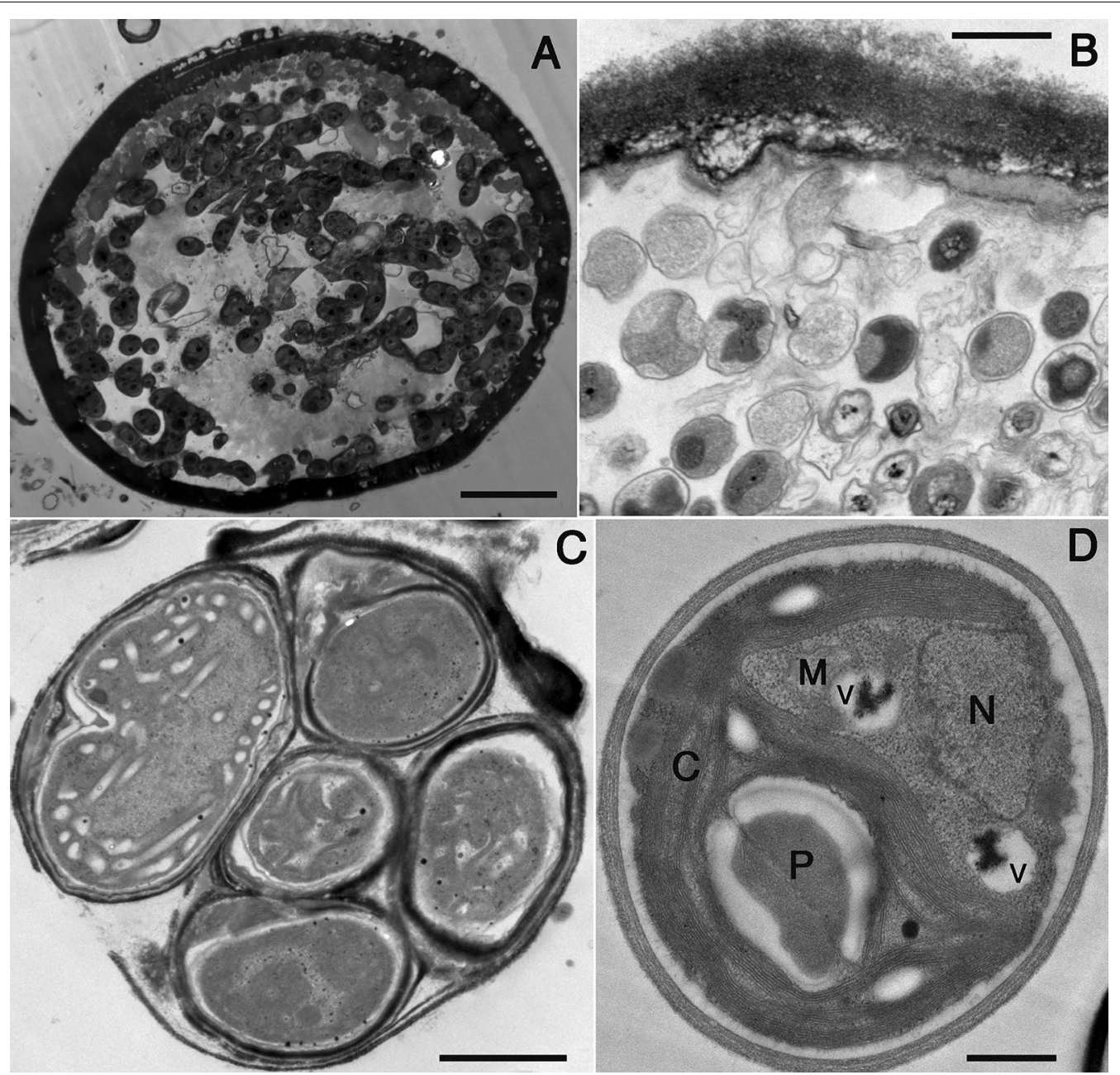

Fig. 2 TDX16 development and transition into TDX16-DE. A Very small TDX16 cells with electron-dense HGBs multiplied by asymmetric division in the senescent H. pluvialis cell, scale bar $5 \mu \mathrm{m}$. B Small DTX16 cells filled up the cellular space of a senescent H. pluvialis cell, scale bar $0.5 \mu \mathrm{m}$. C Five TDX16 cells within a sporangium, scale bar $1 \mu \mathrm{m}$. D A TDX16-DE cell contains a large "e-shaped" chloroplast (C) with an embedded pyrenoid (P), a nucleus $(\mathrm{N})$, a mitochondrion $(\mathrm{M})$ and two vacuoles $(\mathrm{V})$, scale bar $0.5 \mu \mathrm{m}$ 
bacteria and cyanobacteria are close relatives sharing similar structures and behaviors, it is possible that some bacteria, like TDX16, are capable of prokaryote-toeukaryote transition under the similar conditions. If so, the bacteria within normal/cancer cells of multicellular eukaryotes may develop into new single-celled eukaryotes: PCCs/SCCs. Consistent with this notion, PCCs/ SCCs formation really share striking similarities with TDX16 development and TDX16-to-TDX16-DE transition (Figs. 1, 2):

1. Similar to TDX16 development, the nascent PCCs/ SCCs (1) are formed within PGCs/PGCCs, (2) reproduce by asymmetric division, which is usually interpreted as the unachievable division of PGCs/PGCCs or subnuclei, (3) aggregate into spheroids [28, 31, 33, $39,41-46]$, and (4) are released after PGCs/PGCCs burst $[28,41]$.

2. The newly released/formed PCCs/SCCs are very small and undifferentiated $[15,35,46,65,66]$ con- taining only "micronuclei" [27, 35], which are, however, not the real nuclei but the single-membranebounded DNA storage bodies (DSBs), similar to HGBs in TDX16 (Fig. 2A, B) [3]. So, just as TDX16, PCCs/SCCs are initially absent of organelles.

3. Although how and when organelles are developed in the small PCCs/SCCs remain unknown, it is certain that with the enlargement of latter organelles are formed de novo in a way akin to organelle biogenesis in TDX16 that resulted in its transition into eukaryotic TDX16-DE (Fig. 2D) [3].

\section{Presentation of the hypothesis}

Based on the above analyses and comparisons, we propose the bacterial origin of cancer cells $(\mathrm{BOCC})$ that PCCs/SCCs arise from bacteria through 8 steps (Fig. 3):

1. Under the stress of physical, chemical or biological factors, normal cells/PCCs undergo senescence,

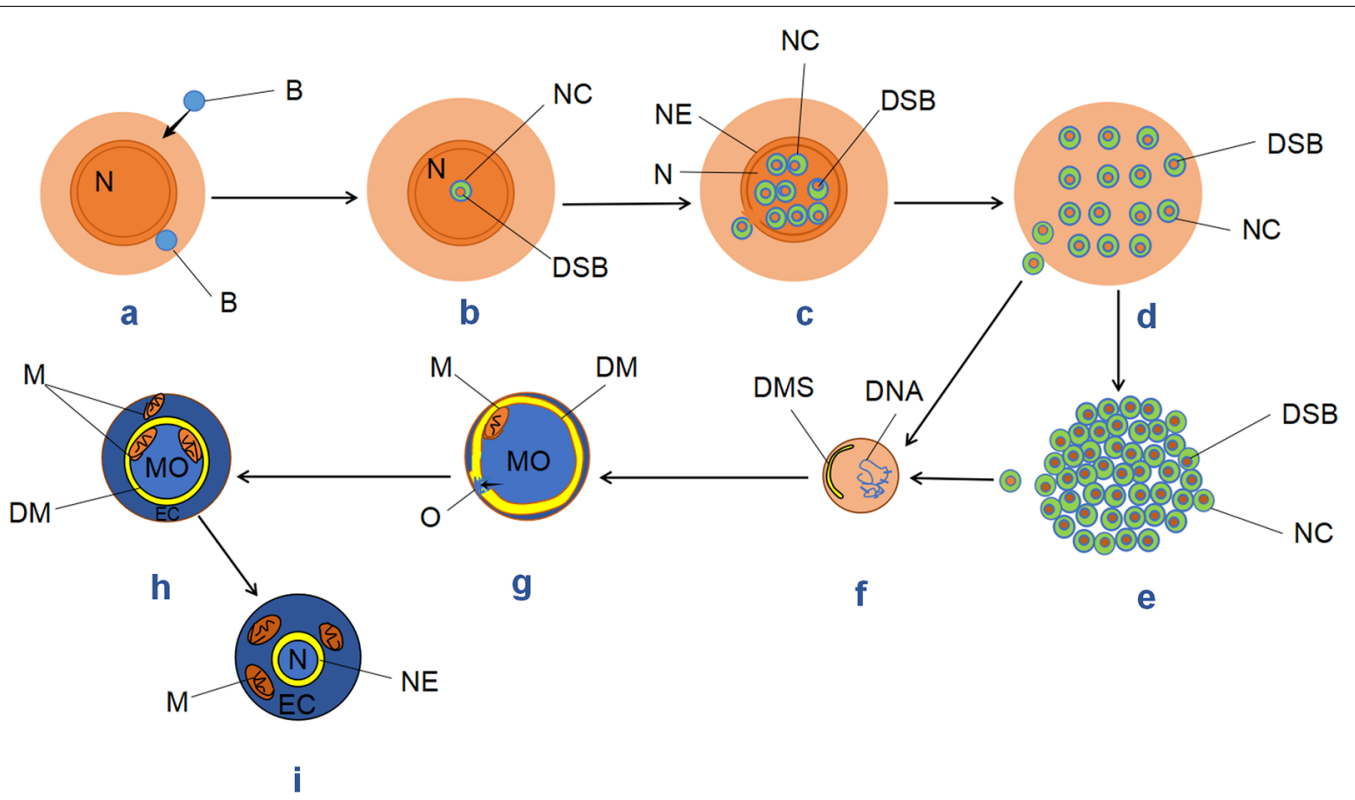

Fig. 3 Cartoon illustrating the formation of cancer cells. a The normal cell/PCC undergoes senescence and bloats into a PGC/PGCC with a large nucleus ( $N$ ). leading to the activation of the dormant intracellular bacterium (B) and the invasion of the extracellular bacterium. $\mathbf{b}$ The bacterium intrudes into the large PGC/PGCC nucleus, takes up the nuclear DNA and retains the obtained DNA in DSB, and thus turns into the small nascent cancer cell (NC): PCC/SCC. c NC multiplies in the nucleus by asymmetric division, some of which penetrate the nuclear envelope (NE) into the cytoplasm. $\mathbf{d}$ All NCs enter cytoplasm after the rupture of NE, and continue to proliferate. During this process, some NCs protrude and escape from the necrotic PGCs/PGCCs; while most NCs aggregate into a spheroid. e A spheroid consist of NCs is liberated from the ruptured PGCs/PGCCs. $\mathbf{f}$ As NC increases in size, DSB disrupts and thus the acquired eukaryotic DNA and the bacterial one fragments and hybridizes into a hybrid genome; concurrently, a peripheral double membrane segment (DMS) is synthesized by fusion of the cytoplasmic membrane-derived vesicles. $\mathbf{g}$ NC further enlarges, DMS extends into a closed double membrane (DM), enclosing the total cytoplasm, and thus gives rise to a single multifunctional organelle (MO). Inside $\mathrm{MO}$, a mitochondrion ( $\mathrm{M}$ ) is assembled by encapsulating the selected relevant components (e.g., DNA) with the double membrane synthesized by fusion of the inner DM membrane-derived vesicles; meanwhile, a small opening $(\mathrm{O})$ is formed on DM allowing the selective release of $\mathrm{MO}$ matrix. $\mathbf{h}$ The released $\mathrm{MO}$ matrix builds up the eukaryotic cytoplasm (EC), and the newly assembled mitochondrion detaches from $\mathrm{MO}$ into $\mathrm{EC}$; while new mitochondria continue to develop in $\mathrm{MO}$, resulting the diminishment of $\mathrm{MO}$. i After all mitochondria enter $\mathrm{EC}$, MO dwindles into a nucleus (N), such that NC develops into a large mature PCC/SCC 
turn into PGCs/PGCCs with large nuclei and lose the ability to control the intracellular bacteria and keep out the extracellular ones, leading to activation of the former and invasion of the latter (Fig. 3a).

2. The intracellular bacteria usually reside in PGCs/ PGCCs cytoplasm. Occasionally, one or several bacteria intrude into the large PGCs/PGCCs nuclei, take up the active nuclear DNAs (including related proteins) and retain the acquired DNAs in the replicable membrane-delimited DSBs. As such, the DSB-containing bacteria in PGCs/PGCCs turn into the small nascent cancer cells (NCs): PCCs/SCCs (Fig. 3b), which are usually mistaken for "small nuclei" or "micronuclei" in PGCs/PGCCs and "multinucleated giant cells"/"multinucleated giant cancer cells".

3. The small NCs reproduce via asymmetric division in PGCs/PGCCs nuclei, some of which penetrate the nuclear envelope (NE) into the cytoplasm (Fig. 3c).

4. All NCs enter cytoplasm after the rupture of NE, and continue to proliferate at the expense of degraded organelles and cytoplasm. During this process, some NC protrude and escape from the necrotic PGCs/ PGCCs (Fig. 3d); while most NCs aggregate into a spheroid, which is liberated after the burst of PGCs/ PGCCs (Fig. 3e).

5. As NC increases in size, DSB disrupts and thus the acquired eukaryotic DNAs and the bacterial DNAs fragment and hybridize into a hybrid genome in a way similar to the genome assembly of TDX16-DE [3] and "chromothripsis" [67]; concurrently, a peripheral double membrane segment (DMS) is synthesized by fusion of the cytoplasmic membrane-derived vesicles (Fig. 3f).

6. NC further enlarges, DMS extends into a closed double membrane (DM) enclosing the total cytoplasm, and thus gives rise to a single multifunctional organelle (MO). Inside $\mathrm{MO}$, mitochondria are assembled by encapsulating the relevant components (e.g., DNAs) with the double membranes synthesized by fusing the inner DM membrane-derived vesicles; meanwhile, a small opening $(\mathrm{O})$ is formed on $\mathrm{DM}$ allowing the selective release of MO matrix (Fig. 3g).

7. The released MO matrix builds up the eukaryotic cytoplasm (EC), and the newly assembled mitochondria detach from MO into EC; while new mitochondria are developed continuously in $\mathrm{MO}$, resulting in the diminishment of $\mathrm{MO}$ (Fig. 3h).

8. After all mitochondria enter EC, MO dwindles into a nucleus $(\mathrm{N})$, such that $\mathrm{NCs}$ develop into large mature PCCs/SCCs (Fig. 3i).

In the way described above, new SCCs can be developed successively from the same or different species of bacteria, which inevitably result in the increased heterogeneity, genetic instability and endless complexity of cancer cells in vivo and in vitro. Hence, PCCs, SCCs and the subsequent new SCCs look superficially like the putative "cancer stem cells" [68] in cancer progression.

\section{Evidences supporting the BOCC hypothesis}

1. There are $10 \times$ more bacterial cells than human cells in the human body [69].

2. Bacteria play a key role in carcinogenesis. Helicobacter pylori is a definite carcinogen for gastric cancer [70]. Many other bacteria are related with various cancers, such as Salmonella typhi [71], Chlamydia pneumoniae [72], Mycoplasma hominis [73], Bacteroides fragilis [74], Streptococcus bovis [75], Escherichia coli [76], Fusobacterium spp. [77]. and Neisseria gonorrhoeae [78].

3. Like bacteria and single-celled eukaryotes (protists, e.g., yeast), cancer cells can grow in agar medium and form colonies [79], proliferate in the absence of anchorage in vitro [80] and ferment glucose in the absence of oxygen (anaerobic fermentation) with the production of lactic acid [81].

4. Cancer cell genomes were assembled from DNA fragments all at once in a single catastrophic event (chromothripsis) [67].

5. Cancer cell genomes contain bacterial DNA [82-84].

6. Genes of ancient and unicellular origin are highly and preferentially expressed during tumorigenesis [85, 86].

\section{Testing the hypothesis}

The following BOCC-based predictions can be used for testing the hypothesis:

1. No bacteria, no cancer. So, after eliminating the intracellular bacteria, normal cells can not "transform" into cancer cells in any conditions.

Testing Inducing the bacteria-containing and bacteria-free normal cells with different carcinogens and infectious agents and tracking their changes.

2. The "small nuclei" in "multinucleated giant cells" /"multinucleated giant cancer cells" and PGCs/ PGCCs as well as the chromothripsis-related "micronuclei" [87-89] are the bacteria-derived nascent PCCs/SCCs, containing bacterial and host's DNAs. Testing Isolating the "small nuclei" and "micronuclei", sequencing their DNAs and identifying bacterial DNAs. 
3. The "small nuclei" and "micronuclei" mentioned above have no organelles but DSBs, which enlarge and develop into eukaryotic cancer cells by de novo organelle biogenesis after disruption of DSBs.

Testing Cultivating the isolated "small nuclei" and "micronuclei" and track microscopically the changes of cellular structure.

4. There is an outer membrane external to the cytoplasmic membrane of "small nuclei", "micronuclei" and PCCs/SCCs (except those that arose from the cell wall-less bacteria e.g., Mycoplasma), while the cytoplasmic membrane is capable of oxidative phosphorylation and lipid synthesis.

Testing Detecting the outer membrane, and identifying the electron carriers of oxidative phosphorylation and the relevant enzymes in the cytoplasmic membrane.

5. PCCs/SCCs genomes contain massive hybrid genes with bacterial gene sequences.

Testing Identification of bacterial DNA sequences in PCCs/SCCs genomes.

\section{Implications of the hypothesis} Clarifying the cause and results of cancer

Cancer cell genomes are formed by hybridizing the acquired eukaryotic DNAs and bacterial ones. Such hybridization inevitably result in (1) gene loses, substitution and synthesis, which are usually ascribed to "mutations" (DNA changes), and (2) aneuploidy and karyotypic heterogeneity, which are considered to be the reasons for genome instability. Therefore, genetic changes and instabilities are not the causes, but the consequences of cancer cell development.

\section{Explaining the reason behind the hallmarks of cancer}

In the light of BOCC the reason behind the hallmarks of cancer [90, 91] become clear. Cancer cells are new bacteria-derived single-celled eukaryotes formed by expression of the hybrid genomes, which inevitably exhibit the characteristics of protists, e.g., "self-sufficiency", "replicative immortality", "invasion and metastasis" and somatic cells, i.e. "angiogenesis", but evade somatic-cell-targeted controls of "growth suppress" and "apoptosis". Indeed, "reprogramming energy metabolism" that cancer cells generate energy via "aerobic glycolysis", i.e. "Warburg effect" [81], is also a characteristic of protists, because the yeast Saccharomyces cerevisiae produce energy via aerobic fermentation [92] called "Crabtree effect" [93]. As to "evading immune destruction", the reasons may be that the cancer-causing bacteria have already developed strategies to evade immune system defenses as indicated by their persistence within the host cells, so the bacteria-derived cancer cells acquire the capability to evade immune destruction.

\section{Clarifying the common role of carcinogens, infectious agents and relating factors in carcinogenesis}

Cancer can be caused by physical and chemical carcinogens [94], infectious agents [95] including viruses [96], bacteria [70] and parasites [97], and related to the factors of organismal aging [98], immunity [99] and inflammation [100]. It is reasonable that these varied carcinogens, infectious agents and relating factors play or link to a common role in carcinogenesis. Such a common role is unknown, but apparently not mutation, because most of the carcinogens and infectious agents are not mutagenic.

According to BOCC theory, senescence of normal cells is the prerequisite for the formation of bacteria-derived cancer cells. Hence, the common role of carcinogens, infectious agents and relating factors in carcinogenesis is inducing or linked to cellular senescence. In general, carcinogens and infectious agents induce cell senescence by (1) causing cell damage and or more or less DNA changes (physical and chemical carcinogens), (2) integrate DNA into host cell genome to interfere cell metabolic activities (viruses), (3) mechanical irritation (parasites), (4) secreting irritant metabolites (bacteria and parasites), (5) inducing chronic inflammation (physical and chemical carcinogens, bacteria, viruses, and parasites) and (6) interfering or inhibiting host's immune system resulting in lowered immunity or immunosuppression (physical and chemical carcinogens, bacteria, viruses, and parasites); while organismal aging is associated with immunity declines and thus cellular senescence.

\section{Providing a new rationale and direction for cancer research, prevention and therapy}

If confirmed, BOCC theory provides a new rationale for cancer research, and a new direction for cancer prevention and therapy. Eliminating the cancer-causing bacteria in the body with antibiotics or other agents, stopping bacteria's acquisition and hybridization of host's DNAs, and developing bacteria-targeted vaccines can prevent cancer and inhibit, to some extent, cancer progression. Identifying the differences between the bacteria-derived cancer cells and normal cells in structure, constitution and metabolism can provide targets for developing drugs and vaccines to eradicate cancer cells in cancer treatment.

\section{Abbreviations}

B: bacteria; BOCC: bacterial origin of cancer cells; DSBs: DNA storage bodies; DM: double membrane; DMS: double membrane segment; EC: eukaryotic cytoplasm; HGB: heterogenous globular body; M: mitochondria; MO: multifunctional organelle; N: nucleus; NC: nascent cancer cells; NE: nuclear 
envelope; O: opening; PCCs: primary cancer cells; PGCs: polyploidy giant cells; PGCCs: polyploid giant cancer cells; SCCs: secondary cancer cells.

\section{Authors' contributions}

The authors make equal contributions for the work. Both authors read and approved the final manuscript.

\section{Acknowledgements}

Not applicable.

\section{Competing interests}

The authors declare that they have no competing interests.

\section{Availability of data and materials}

Not applicable.

\section{Ethics approval and consent to participate}

Not applicable.

\section{Consent for publication}

Not applicable.

\section{Funding}

Self funded by authors.

\section{Publisher's Note}

Springer Nature remains neutral with regard to jurisdictional claims in published maps and institutional affiliations.

Received: 31 July 2018 Accepted: 6 December 2018 Published online: 14 December 2018

\section{References}

1. Weinberg RA. Coming full circle-from endless complexity to simplicity and back again. Cell. 2014;157:267-71.

2. Dong QL, Xing XY, Wu HX, Han Y, Wei XL, Zhang S. Transition of a prokaryotic endosymbiotic cyanobacterium into a eukaryotic green alga. Chem Eng. (China) 2016;44:1-6.

3. Dong QL, Xing XY, Han Y, Wei XL, Zhang S. De novo organelle biogenesis in the cyanobacterium TDX16 released from the green alga Haematococcus pluvialis. BioRxiv. 2017. https://doi.org/10.1101/161463.

4. Earle WR, Schilling EL, Stark TH, Straus NR, Brown MF, Shelton E. Production of malignancy in vitro. IV. The mouse fibroblast cultures and changes seen in the living cells. J Natl Cancer Inst. 1943;4:165-212.

5. Earle WR, Nettleship RA, Schilling EL, Stark TH, Straus NR, Brown MF, Shelton E. Production of malignancy in vitro. V. Results of injections of cultures into mice. J Natl Cancer Inst. 1943;4:213-27.

6. Firor WM, Gey GO. Observations on the conversion of normal into malignant cells. Ann Surg. 1945;121:700-3.

7. Leighton J, Kline I, Orr HC. Transformation of normal human fibroblasts into histologically malignant tissue in vitro. Science. 1956;123:502-3.

8. Barrett JC. A preneoplastic stage in the spontaneous neoplastic transformation of Syrian Hamster embryo cells in culture. Cancer Res. 1980:40:91-4

9. Cram LS, Bartholdi MF, Ray FA, Travis GL, Kraemer PM. Spontaneous neoplastic evolution of Chinese hamster cells in culture: multistep progression of karyotype. Cancer Res. 1983;43:4828-37.

10. Borek C. X-ray-induced in vitro neoplastic transformation of human diploid cells. Nature. 1980;288:776-8.

11. Milo G, DiPaolo JA. Neoplastic transformation of human diploid cells in vitro after chemical carcinogen treatment. Nature. 1978;275:130-2.

12. Stampfer MR, Bartley JC. Induction of transformation and continuous cell lines from normal human mammary epithelial cells after exposure to benzo[a] pyrcne. Proc Natl Acad Sci USA. 1984;82:2394-8.

13. Sachs $L$, Medina $D$. In vitro transformation of normal cells by polyoma virus. Nature. 1961;189:457-8.
14. Shein HM, Enders JF. Transformation induced by simian virus 40 in human renal cell cultures, I. Morphology and growth characteristics. Proc Natl Acad Sci USA. 1962:48:1164-72.

15. Todaro GJ, Green H, Swift MR. Susceptibility of human diploid fibroblast strains to transformation by SV40 virus. Science. 1966;253:1252-4.

16. Defendi V. Transformation in vitro of mammalian cells by polyoma and simian 40 viruses. Progr Exp Tumor Res. 1966;8:125-88.

17. Rhim JS, Jay G, Arnstein P, Price FM, Sanford KK, Aaronson SA. Neoplastic transformation of human epidermal keratinocytes by ADI2-SV40 and Kirsten sarcoma virus. Science. 1985;227:1250-2.

18. Hayflick $L$. The limited in vitro lifetime of human diploid cell strains. Exp Cell Res. 1965:37:614-36.

19. Girardi AJ, Jensen FC, Koprowski H. SV40-induced transformation of human diploid cells: crisis and recovery. J Cell Comp Physiol. 1965;65:69-84.

20. Todaro GJ, Green H. Quantitative studies of the growth of mouse embryo cells in culture and their development into established lines. J Cell Biol. 1963:17:299-313.

21. Moorhead PS, Saksela E. The sequence of chromosome aberrations during SV40 transformation of a human diploid cell strain. Hereditas. 1965;52:271-84

22. Terzi M, Hawkins TSC. Chromosomal variation and the establishment of somatic cell lines in vitro. Nature. 1975;253:361-2.

23. Kaighn ME, Narayan KS, Ohnuki Y, Jones LW, Lechner JF. Differential properties among clones of simian virus 40-transformed human epithelial cells. Carcinogenesis. 1980;1:635-45.

24. Huschtscha LI, Holliday R. Limited and unlimited growth of SV40transformed cells from human diploid MRC-5 fibroblasts. J Cell Sci. 1983:63:77-99.

25. Zitcer EM, Dunnebacke TH. Transformation of cells from the normal human amnion into established strains. Cancer Res. 1957:17:1047-53.

26. Pulvertaft RJV, Davies JR, Weiss L, Wilkinson JH. Studies on tissue cultures of human pathological thyroids. J Path Bact. 1959;77:19-32.

27. Pontén J, Jensen F, Koprowski H. Morphological and virological investigation of human tissue cultures transformed with SV40. J Cell Comp Physiol. 1963;61:145-63.

28. Walen $\mathrm{KH}$. The origin of transformed cells: studies of spontaneous and induced in cell cultures from marsupials, a snail and human amniocytes. Cancer Genet Cytogenet. 2002;133:45-54.

29. Walen KH. Spontaneous cell transformation: karyoplasts derived from multinucleated cells produce new cell growth in senescent human epithelial cell cultures. Vitro Cell Dev Biol Anim. 2004:40:150-8.

30. Walen KH. Budded karyoplasts from multinucleated fibroblast ceils contain centrosomes and change their morphology to mitotic cells. Cell Biol Int. 2005;29:1057-65.

31. Walen $\mathrm{KH}$. Normal human cell conversion to 3-D cancer-like growth: genome damage, endopolyploidy, senescence escape and cell polarity change/loss. J. Cancer Ther. 2011;2:181-9.

32. Sundaram M, Guerrnsey DL, Rajaraman MM, Rajaraman RR. Neosis: a novel type of cell division in cancer. Cancer Biol Therap. 2004;3:207-18.

33. Leikam C, Hufnagel AL, Otto C, Murphy DJ, Muhling B, Kneitz S, Nanda I, Schmid M, Wagner TU, Haferkamp S, Brocker EB, Schartl M, Meierjohann S. In vitro evidence for senescent multinucleated melanocytes as a source for tumor-initiating cells. Cell Death Dis. 2015;6:e1711. https:// doi.org/10.1038/cddis.2015.71.

34. Zhang S, Mercado-Uribe I, Sood A, Bast RC, Liu J. Coevolution of neoplastic epithelial cells and multilineage stroma via polyploid giant cells during immortalization and transformation of mullerian epithelial cells. Genes Cancer. 2016;7:60-72.

35. Buikis I, Harju L, Freivalds T. Origin of microcells in human sarcoma cell line HT1080. Anal Cell Pathol. 1999;18:73-85.

36. Erenpreisa J, Cragg M, Fringes B, Sharakhov I, Illidge T. Release of mitotic descendents by giant cells from irradiated Burkitt's lymphoma cell line. Cell Biol Int. 2000:24:635-48.

37. Erenpreisa J, Salmina K, Huna A, Kosmacek EA, Cragg MS, lanzini F, Anisimov AP. Polyploid tumour cells elicit paradiploid progeny through depolyploidizing divisions and regulated autophagic degradation. Cell Biol Int. 2011;35:687-95

38. Puig PE, Guilly MN, Bouchot A, Droin N, Cathelin D, Bouyer F, et al. Tumor cells can escape DNA-damaging cisplatin through DNA endoreduplication and reversible polyploidy. Cell Biol Int. 2008;32:1031-43. 
39. Ianzini F, Kosmacek EA, Nelson ES, Napoli E, Erenpreisa J, Kalejs M, Mackey MA. Activation of meiosis-specific genes is associated with depolyploidization of human tumor cells following radiation-induced mitotic catastrophe. Cancer Res. 2009;69:2296-304.

40. Weihua Z, Lin Q, Ramoth AJ, Fan D, Fidler IJ. Formation of solid tumors by a single multinucleated cancer cell. Cancer. 2011;117:4092-9.

41. Zhang S, Mercado-Uribe I, Liu J. Generation of erythroid cells from fibroblasts and cancer cells in vitro and in vivo. Cancer Lett. 2013;333:205-12.

42. Zhang S, Mercado-Uribe I, Xing Z, Sun B, Kuang J, Liu J. Generation of cancer stem-like cells through the formation of polyploid giant cancer cells. Oncogene. 2014;33:116-28.

43. Zhang S, Mercado-Uribe I, Liu J. Tumor stroma and differentiated cancer cells can be originated directly from polyploid giant cancer cells induced by paclitaxel. Int J Cancer. 2014;134:508-18.

44. Zhang D, Yang XY, Yang ZD, et al. Daughter cells and erythroid cells budding from pgecs and their clinicopathological significances in colorectal cancer. J Cancer. 2017:8:469-78.

45. Niu N, Zhang J, Zhang N, Mercado-Uribe Zhang, Tao F, Han Z, et al. Linking genomic reorganization to tumor initiation via the giant cell cycle. Oncogenesis. 2026;5:e281. https://doi.org/10.1038/oncsis.75.

46. Niu N, Mercado-Uribe I, Liu J. Dedifferentiation into blastomere-like cancer stem cells via formation of polyploid giant cancer cells. Oncogene. 2017;36:4887-900.

47. Bernhard W, Granboulan N. The fine structure of the cancer cell nucleus. Exp Cell Res. 1963;9(Suppl. 1):19-53.

48. Kleinfeld R, Melnick JL. Cytological aberrations in cultures of normal monkey kidney epithelial cells. J Exp Med. 1958;107:599-608.

49. Reissig M, Howes DW, Melnick JL. Sequence of morphological changes in epithelial cell cultures infected with polio virus. J Exp Med. 1956:104:289-304.

50. Moyer AW, Wallace R, Cox HR. Limited growth period of human lung cell lines transformed by simian virus 40. J Nat Cancer Inst. 1964;33:227-36.

51. Lamond Al, Earnshaw WC. Structure and function in the nucleus. Science. 1998;280:547-53.

52. Russell W. An address on a characteristic organism of cancer. Br Med J. 1890;2:1356-60.

53. Wuerthele-Caspé V, Alexander-Jackson E, Anderson JA, Hillier J. Cultural properties and pathogenicity of certain microorganisms obtained from various proliferative and neoplastic diseases. Am J Med Sci. 1950;220:638-46

54. Edward GA, Fogh J. Fine structure of pleuropneumonia-like organisms in pure culture and in infected tissue culture cells. J Bacteriol. 1960;79:267-76

55. Hummeler K, Armstrong D, Tomassini N. Cytopathogenic mycoplasmas associated with two human tumors. II. Morphological aspects. J Bacteriol. 1965;90:511-6.

56. Hummeler K, Armstrong D. Observations on mycoplasma strains in tissue culture. Ann N Y Acad Sci. 1967;143:622-5.

57. Taylor-Robinson D, Davies HA, Sarathchandra P, Furr PM. Intracellular location of mycoplasmas in cultured cells demonstrated by immunocytochemistry and electron microscopy. Int J Exp Pathol. 1991;72:705-14.

58. Lo SC, Hayes MM, Tully JG, Wang RY, Kotani H, Pierce PF, Rose DL, Shih JW. Mycoplasma penetrans sp. nov., from the urogenital tract of patients with AIDS. Int J Syst Bacteriol. 1992;42:357-64.

59. Jensen JS, Biom J, Lind K. Intracellular location of Mycoplasma genitalium in cultured Vero cells as demonstrated by electron microscopy. Int J Exp Pathol. 1994;75:91-8.

60. Ueno PM, Timenetsky J, Centonze VE, Wewer JJ, Cagle M, Stein MA, Krishnan M, Baseman JB. Interaction of Mycoplasma genitalium with host cells: evidence for nuclear localization. Microbiology. 2008; 154:3033-41.

61. McGowin CL, Popov VL, Pyles RB. Intracellular Mycoplasma genitalium infection of human vaginal and cervical epithelial cells elicits distinct patterns of inflammatory cytokine secretion and provides a possible survival niche against macrophage-mediated killing. BMC Microbiol. 2009;9:139. https://doi.org/10.1186/1471-2180-9-139.

62. Dong QL, Zhao XM. In situ carbon dioxide fixation in the process of natural astaxanthin production by a mixed culture of Haematococcus pluvialis and Phaffia rhodozyma. Catal Today. 2004;98:537-44.
63. Dong QL, Zhao XM, Xing XY, Hu JZ, Gong JX. Concomitant $\mathrm{NH}_{4}{ }^{+}$secretion during astaxanthin synthesis in Haematococcus pluvialis under high irradiance and nitrogen deficient conditions. Chin J Chem Eng. 2007;15:162-6.

64. Dong QL, Li ZW, Xing XY, Chen B. Discovery of an endophytic cyanobacterium in Haematococcus pluvialis. J Hebei Univ Technol. 2011:40:1-5.

65. Woodworth CD, Bowden PE, Doninger J, Pirisi L, Barnes W, Lancaster WD, DiPaolo JA. Characterization of normal human exocervical epithelial cells immortalized in vitro by papillomavirus types 16 and 18 DNA. Cancer Res. 1988:48:4620-8.

66. Romanov SR, Kozakiewics BK, Hoist CR, Stampfei MR, Haupt LM, Tlsty TD. Normal human mammary epithelial cells spontaneously escape senescence and acquire genomic changes. Nature. 2001;409:633-7.

67. Stephens PJ, Greenman CD, Fu B, Yang F, Bignell GR, Mudie LJ, Pleasance $E D$, Lau KW, Beare D, Stebbings LA, et al. Massive genomic rearrangement acquired in a single catastrophic event during cancer development. Cell. 2011:144:27-40.

68. Reya T, Morrison SJ, Clarke MF, Weissman IL. Stem cells, cancer, and cancer stem cells. Nature. 2001;414:105-11.

69. Luckey TD. Introduction to the ecology of the intestinal flora. Am J Clin Nutr. 1970;23:1430-2.

70. Kuper H, Adami HO, Trichopoulos D. Infections as a major preventable cause of human cancer. J Intern Med. 2000;248:171-83.

71. Dutta U, Garg PK, Kumar R, Tandon RK. Typhoid carriers among patients with gallstones are at increased risk for carcinoma of the gallbladder. Am J Gastroenterol. 2000;95:784-7.

72. Laurila AL, Anttila T, Laara E, Bloigu A, Virtamo J, Albanes D, Leinonen M, Saikku P. Serological evidence of an association between Chlamydia pneumoniae infection and lung cancer. Int J Cancer. 1997;74:31-4.

73. Barykova YA, Logunov DU, Shmarov MM, Vinarov AZ, Fiev DN, Vinarova NA, Rakovskaya IV, Baker PS, Shyshynova I, Stephenson AJ, Klein EA, Naroditsky BS, Gintsburg AL, Gudkov AV. Association of Mycoplasma hominis infection with prostate cancer. Oncotarget. 2011;2:289-97.

74. Sears CL, Pardoll DM. Perspective: alpha-bugs, their microbial partners, and the link to colon cancer. J Infect Dis. 2011;203:306-11.

75. Biarc J, Nguyen IS, Pini A, Gosse F, Richert S, Thierse D, et al. Carcinogenic properties of proteins with pro-inflammatory activity from Streptococcus infantarius (formerly S. bovis). Carcinogenesis. 2004;25:1477-84.

76. Martin HM, Campbell BJ, Hart CA, Mpofu C, Nayar M, Singh R, Englyst $\mathrm{H}$, Williams HF, Rhodes JM. Enhanced Escherichia coli adherence and invasion in Crohn's disease and colon cancer. Gastroenterol. 2004;127:80-93.

77. Rubinstein MR, Wang X, Liu W, Hao Y, Cai G, Han YW. Fusobacterium nucleatum promotes colorectal carcinogenesis by modulating E-cadherin/beta-catenin signaling via its FadA adhesin. Cell Host Microbe. 2013;14:195-206.

78. Caini S, et al. Sexually transmitted infections and prostate cancer risk: a systematic review and meta-analysis. Cancer Epidemiol. 2014;38:329-38.

79. Macpherson I, Montagnier L. Agar suspension culture for the selective assay of cells transformed by polyoma virus. Virology. 1964;23:291-4.

80. Shin S, Freedman VH, Risser R, Pollack R. Tumorigenicity of virustransformed cells in nude mice is correlated specifically with anchorage independent growth in vitro. Proc Natl Acad Sci USA. 1975;72:4435-9.

81. Warburg O. On the origin of cancer cells. Science. 1956;123:309-14.

82. Riley DR, Sieber KB, Robinson KM, White JR, Ganesan A, Nourbakhsh S, Dunning Hotopp JC. Bacteria-human somatic cell lateral gene transfer is enriched in cancer samples. PLoS Comput Biol. 2013;9(6):1003107. https://doi.org/10.1371/journal.pcbi.1003107.

83. Sidhoo S, Rosales JL, Lee KY. Integration of a bacterial gene sequence into a chronic eosinophilic leukemia patient's genome as part of a fusion gene linker. Biomark Res. 2017;5:20. https://doi.org/10.1186/ s40364-017-0101-z.

84. Al-Abbas MJA, Abdul-Ridha LA. Practical genetic study confirming and identifying the horizontal gene transfer (HGT) of bacterial DNA (16SrDNA gene) integrated in the DNA of cancer patients. Merit Res J Med Med Sci. 2017:5(2):60-71.

85. Wu A, Zhang Q, Lambert G, Khin Z, Gatenby RA, Kim HJ, Pourmand N, Bussey K, Davies PC, Sturm JC, Austin RH. Ancient hot and cold genes 
and chemotherapy resistance emergence. Proc Natl Acad Sci USA. 2015;112(33):10467-72.

86. Trigos AS, Pearson RB, Papenfuss AT, Goode DL. Altered interactions between unicellular and multicellular genes drive hallmarks of transformation in a diverse range of solid tumors. Proc Natl Acad Sci USA. 2017;114:6406-11.

87. Crasta K, Ganem NJ, Dagher R, Lantermann AB, Ivanova EV, et al. DNA breaks and chromosome pulverization from errors in mitosis. Nature. 2012:482:53-8.

88. Hatch EM, Fischer AH, Deerinck TJ, Hetzer MW. Catastrophic nuclear envelope collapse in cancer cell micronuclei. Cell. 2013;154:47-60.

89. Zhang CZ, Spektor A, Cornils H, Francis JM, Jackson EK, et al. Chromothripsis from DNA damage in micronuclei. Nature. 2015;522:179-84.

90. Hanahan D, Weinberg RA. The hallmarks of cancer. Cell. 2000;100:57-70.

91. Hanahan D, Weinberg RA. Hallmarks of cancer: the next generation. Cell. 2011;144:646-74.

92. De Deken RH. The Crabtree effect: a regulatory system in yeast. J Gen Microbiol. 1966:44:149-56.

93. Crabtree HG. Observations on the carbohydrate metabolism of tumors. Biochem J. 1929:23:536-45.
94. Harris CC. Chemical and physical carcinogenesis: advances and perspectives for the 1990s. Cancer Res. 1991;51:5023-44.

95. De Martel C, Ferlay J, Franceschi S, Vignat J, Bray F, Forman D, Plummer M. Global burden of cancers attributable to infections in a review and synthetic analysis. Lancet Oncol. 2008;2012(13):607-15.

96. Chang Y, Moore PS, Weiss RA. Human oncogenic viruses: nature and discovery. Phil Trans R Soc B. 2017;372:20160264.

97. Fried B, Reddy A, Mayer D. Helminths in human carcinogenesis. Cancer Lett. 2011;305:239-49.

98. Palmer S, Albergante L, Blackburn CC, Newman TJ. Thymic involution and rising disease incidence with age. Proc Natl Acad Sci USA. 2018;115:1883-8.

99. Grivennikov SI, Greten FR, Karin M. Immunity, inflammation, and cancer. Cell. 2010:140:883-99.

100. Elinav E, Nowarsk R, Thaiss CA, Hu B, Jin CC, Flavell RA. Inflammationinduced cancer: crosstalk between tumours, immune cells and microorganisms. Nat Rev Cancer. 2013;13:759-71.
Ready to submit your research? Choose BMC and benefit from:

- fast, convenient online submission

- thorough peer review by experienced researchers in your field

- rapid publication on acceptance

- support for research data, including large and complex data types

- gold Open Access which fosters wider collaboration and increased citations

- maximum visibility for your research: over $100 \mathrm{M}$ website views per year

At BMC, research is always in progress.

Learn more biomedcentral.com/submissions 